\title{
GERENCIAMENTO DE CRISE: ESTUDO DE CASO DA MARCA ADES NAS REDES SOCIAS
}

\author{
Thamires de Paulo Fonseca
}

Universidade do Oeste Paulista - UNOESTE. Pós-graduação em Gestão em Marketing e Comunicação, Presidente Prudente-SP. E-mail: fonseeca@folha.com.br

\section{RESUMO}

Esse artigo analisou o Gerenciamento de Crise realizado pela equipe de comunicação do suco AdeS, fabricado pela Unilever Brasil, tendo como plano de fundo sua atuação na página da empresa no Facebook. Em março de 2013 a linha de suco, dessa marca, apresentou problemas na linha de produção influenciando diretamente na qualidade do produto. Ele precisou ser retirado do mercado e vários consumidores relataram nessa rede a indignação sob o ocorrido. Diante da crise, a empresa ignorou as reclamações dos clientes se ausentando da página o que provocou especulações sobre o real problema enfrentado e potencializou a crise e a desconfiança dos consumidores.

Palavras-chave: comunicação, crise, assessoria, gerenciamento e Facebook.

\section{CRISIS MANAGEMENT: A CASE STUDY IN BRAND ADES NETWORK MEMBERS}

\begin{abstract}
This paper analyzed the Crisis Management conducted by the communications team AdeS juice, manufactured by Unilever Brazil, having as background its performance in the company's Facebook page. In March 2013 the line of juice, this brand, presented problems in the production line directly influencing the quality of the product. He had to be taken off the market and several consumers reported that network indignation in what happened. Faced with the crisis, the company ignored customer complaints are absent from the page that sparked speculation about the real problem faced and potentiated the crisis and lack of consumer confidence.
\end{abstract}

Keywords: communication, crisis counseling, management and Facebook. 


\section{INTRODUÇÃO}

Em 13 de março de 2013, a empresa Unilever Brasil, informou que detectou um problema na qualidade, em aproximadamente 96 unidades, do produto AdeS Maçã 1,5l, que o tornava impróprio para o consumo. O produto havia sido distribuído em três Estados brasileiros. Segundo o pronunciamento da empresa por meio de nota em seu site "Nessas unidades, foi identificada uma alteração no seu conteúdo decorrente de uma falha no processo de higienização, que resultou na ênfase de embalagens com solução de limpeza". Antes do pronunciamento oficial da empresa, por meio da nota, o assunto já havia ganhado destaques nas redes sociais e na imprensa nacional.

Em sua página na rede social, Facebook, os gestores da página, não responderam todos os questionamentos de seus seguidores sobre adulteração em sua linha de sucos, aumentando os rumores na rede. Diante disso, o objetivo desse artigo é refletir sobre o Gerenciamento de Crise nas Redes Sociais analisando o caso de mobilização dos consumidores de suco AdeS, fabricado pela Unilever Brasil, tendo como plano de fundo sua Fan Page no Facebook.

\section{FUNDAMENTAÇÃO METODOLÓGICA}

Este estudo tem como abordagem a pesquisa qualitativa, pois o trabalho delimita um corte temporal-espacial. A autora busca visualizar o contexto do objeto estudado e compreender melhor o fenômeno. Marconi e Lakatos (2006, p. 269) afirmam que a:

Metodologia qualitativa preocupa-se em analisar e interpretar aspectos mais profundos, descrevendo a complexidade do comportamento humano. Fornece análise mais detalhada sobre as investigações, hábitos, atitudes, tendências de comportamento [...]

O método escolhido para a realização deste artigo é o estudo de caso, porque a integrante busca analisar com maior profundidade o assunto. Segundo Lüdke e André, o estudo de caso pode ser uma estratégia simples e específica ou complexa e abstrata e deve ser sempre bem delimitado, pois o tema estudado representa um potencial único que focaliza na realidade de modo complexo e contextualizado.

A participante deste projeto realizou uma pesquisa bibliográfica. Segundo Marconi e Lakatos (2010, p. 166) a finalidade é "[...] colocar o pesquisador em contato direto com tudo o que foi escrito, dito ou filmado sobre determinado assunto, inclusive conferências seguidas de debates que tenham sido transcritos por alguma forma, quer publicadas, quer gravadas."

Dessa forma, as autoras (2010, p. 166) explicam que “[...] a pesquisa bibliográfica não é 
mera repetição do que já foi dito ou escrito sobre certo assunto, mas propicia o exame de um tema sob novo enfoque ou abordagem, chegando a conclusões inovadoras."

Uma vez explicado como a metodologia foi empregada no trabalho, chega o momento de adentrar no objeto de estudo.

\section{RESULTADOS}

Essa pesquisa nasce do desejo de analisar como a Unilever Brasil reagiu diante da crise em sua linha de sucos que foi assunto em várias rede sociais, como o Facebook. Forni lembra que "A comunicação hoje é praticamente instantânea. Nesse cenário, o pipocar de uma crise pode abalar toda a estrutura da empresa se a comunicação não for bem administrada." Ou seja, uma única crise pode afetar todo o trabalho de construção de imagem feito por anos. É preciso considerar que toda a empresa, de grande ou pequeno porte não está livre de uma crise. Para evitar situações criticas os comunicadores devem adotar com antecedência o planejamento preventivo, que forneça meios para lidar com os momentos de crise. (NEVES, 2005)

Bueno (2005, p. 12) ressalta que “[...] é necessário considerar que a comunicação empresarial não flui no vazio [...]", por tanto para que a comunicação nas empresas seja eficaz ela precisa ser estratégica e planejada, para isso, os responsáveis pela comunicação na empresa precisam estar atentos ao que pode se tornar crise e manter o controle disso, Souza (2006) lembra que "Quando a mídia assume o controle das informações relacionadas aos assuntos da crise, a instituição fica em desvantagem e pode perder o controle da situação."

Um suco estragado, com características estranhas, um procedimento de segurança que falhou e resultou na contaminação da linha de produtos. Essas são algumas das crises que o setor de comunicação do objeto de estudo deveria prever, já que as empresas estão sujeitas a crises, que com a popularização das redes sociais ganharam um agravante. Neves (2005), a partir de uma entrevista, caracteriza a crise de três formas. A primeira causada por um gerenciamento ruim, ou seja, problemas de gestão, o segundo tipo são as crises em que a empresa se envolve em crimes, como sonegação de impostos. Por fim, crises eventuais como é o caso dos sucos AdeS e a repercussão no Facebook.

Crise não é produto de geração espontânea. É um processo com começo, meio e fim. E, normalmente, quando está no começo os gestores da empresa não têm a percepção para saber que uma crise está começando. (MELO, 2005 apud NEVES, 2005, p. 15)

Como foi dito, as crises podem acontecer com qualquer empresa. Geralmente elas poderiam ter sido previstas pela equipe e logo, a solução também. Mas, se antevemos as crises 
porque elas ainda acontecem? Neves (2005) discorre que "à diversidade de tipos de crise, ocorridas cada qual a sua maneira, e motivadas por fatores específicos são dificilmente cabíveis a uma fórmula única de prevenção." portanto, se não é possível evitar todos os problemas o melhor a fazer é se planejar.

Quando a crise acontece é importante não mentir e não fugir da imprensa ou do público, porque eles necessitam de uma resposta "[...] e suas declarações devem ser transparentes e precisas." (Sousa, 2006, p. 40). A preparação para essas situações requerem algumas medidas de prevenção. Textos-padrão podem ser utilizados, porém Sousa (2006) argumenta que "é fundamental que a assessoria de comunicação prepare um texto informativo descrevendo o fato ocorrido e enfatizando as providências tomadas pela empresa."

Sousa (2006) ressalta ainda que:

Falar sobre o problema de uma maneira direta sem esconder informações pode reduzir a duração da cobertura. Ao divulgar todas as informações na primeira notícia, restará pouca ou nenhuma informação nova para ser divulgada pela mídia nas próximas edições. Anunciar a real situação do problema acalma o público atingido e mostra respeito pelo consumidor, acabando com os boatos e restabelecendo a confiança. Dizer logo tudo o que há para dizer faz a empresa ser vista de maneira mais favorável em momentos difíceis.

No momento de crise, recomenda-se que o setor de comunicação centralize as ações e que treine uma pessoa para falar em nome da empresa. No caso do objeto de estudo, e dos problemas na rede social determinada, a empresa se pronunciou sobre o assunto por meio de nota, apenas duas vezes. O próximo capítulo analisa como foram essas notas e repercussão causada por elas.

\section{DISCUSSÃO}

A empresa Unilever Brasil emitiu o seguinte comunicado sobre os problemas em sua linha de produção no dia 13 de março de 2013, no Facebook:

Pessoal,

Queremos comunicar a vocês em primeira mão um problema que infelizmente foi detectado em um de nossos lotes. Cerca de 96 unidades do produto AdeS Maça 1,5I (lote AGB 25, fabricado em 25/02/2013, com validade até 22/12/2013) estão inapropriadas para o consumo. Os produtos desse lote foram distribuídos nos Estados de São Paulo, Rio de Janeiro e Paraná.

Nessas unidades, foi identificada uma alteração no seu conteúdo decorrente de uma falha no processo de higienização, que resultou em embalagens contendo solução de limpeza.

O consumo do produto nessas condições pode causar queimadura. 
A falha identificada já foi solucionada, os produtos existentes nos pontos de venda já estão sendo recolhidos.

Mesmo assim, pedimos que vocês verifiquem se o produto que têm em casa faz parte do lote mencionado. Se for esse o caso, não consumam e entrem em contato conosco gratuitamente pelo SAC no 0800707 0044, das $8 \mathrm{~h}$ às $20 \mathrm{~h}$ ou pelosac@ades.com.br

Os produtos AdeS não correspondentes a esse lote entram-se em perfeitas condições para o consumo.

Reforçamos nosso compromisso com nossos consumidores e os rigorosos controles de qualidade.

O comunicado teve 166 comentários, 727 compartilhamentos, 178 opções de curtir. Dentre os comentários havia piadas, reclamações e dúvidas sobre o que realmente tinha acontecido e até que ponto era prejudicial à saúde dos consumidores. Foram 15 comentários de usuários até que a empresa se posicionasse novamente, ela fez uma postagem direcionada para um seguidor, os outros foram totalmente ignorados. Dessa maneira, os comentários seguiram e as respostas em resumo eram iguais, quando havia dúvida sobre os lotes eles postavam o texto resumido do comunicado e se houvesse problemas com a ingestão pediam para conversar via inbox. Como dissemos no capítulo anterior ignorar os fatos pode ser um problema.

Mesmo a empresa emitindo um comunicado e respondendo alguns dos seguidores as reclamações continuaram, em partes porque a empresa parou de responder no 16/03 e os comentários seguiram até 26/03 e quem não teve resposta não gostou da atitude da empresa, como é o caso da Rosangela Novais que postou o seguinte comentário, que não teve resposta:

Vamos lá: observando os comentários percebi que apenas alguns deles tiveram resposta. A Ades simplesmente parou de responder seus consumidores, tudo bem erros acontecem, mas acredito que essa nota só foi publicada porque alguém de alguma forma levou isso para mídia... e se isso não acontecesse eu duvido que a Ades divulgaria por conta própria. Será que não está na hora de nós consumidores pararmos para pensar? eles não estão assumindo o erro apenas estão se defendendo. Cadê o respeito ao consumidor todas as postagem precisam de respostas... por favor!!!!

No dia 20 de março houve mais uma nota divulgada na página oficial da empresa no Facebook, que possui 1,3 milhões de seguidores, essa nota teve 428 compartilhamentos, 272 opções de curtir e 560 comentários. A empresa se pronunciou nos comentários apenas 7 vezes, em todos os casos as mensagens foram direcionadas para uma pessoa específica e cinco deles continham o mesmo conteúdo. A primeira resposta aconteceu um dia após a emissão da nota e para responder uma postagem que continha uma imagem do suco com um fungo dentro, as 
outras foram dúvidas aleatórias. A falta de respostas deixou os seguidores com mais motivos para reclamar e foi isso que eles fizeram. Mesmo a empresa não emitindo mais notas sobre o assunto os comentários continuaram por mensagens enviadas, alguns deles com imagens dos fungos.

Para Sousa (2006) "Quando a empresa for indagada em relação a assuntos que não são de sua responsabilidade, deve agir prontamente contra as acusações injustas." A Unilever não respondeu todas as dúvidas dos usuários, e também não agiu contra as acusações injustas. Ela poderia ter bloqueado as mensagens para a visualização de outros usuários, evitando que outros compartilhassem as imagens e os comentários negativos. Ressalta-se que não é possível mensurar a quantidade total dos compartilhamentos, uma vez publicado os seguidores podem compartilhar em seus perfis e essa ação pode se repetir inúmeras vezes.

\section{CONCLUSÃO}

Durante a produção do artigo a autora levou em consideração como a Unilever Brasil gerenciou a crise em sua página no Facebook. Chegou-se a conclusão que a falta de critério para responder as indagações dos usuários deixou os seguidores insatisfeitos. A empresa poderia ter utilizado inúmeros recursos para responder aos usuários e para informá-los. Apenas uma parte da linha de sucos foi contaminada, a empresa poderia ter deixado isso mais claro aos seus clientes. Ou seja, poderia demonstrar por vídeos na própria rede, por exemplo, quais os números dos lotes de sucos alterados e onde os consumidores poderiam ver isso.. Sem entender onde procurar, vários usuários deixaram perguntas na nota, querendo saber se os produtos que tinham em suas casas estavam contaminados.

Outra maneira de utilizar o vídeo para acalmar as pessoas é mostrar como funciona os processos de armazenagem e o que foi feito para que problemas como esse não ocorram mais. Ao invés disso, as notas vieram em um intervalo de dias e todas as outras manifestações foram ignoradas. As mensagens deixadas com imagens se multiplicaram e não foi apresentado nenhum culpado ou garantias de que agora está tudo bem.

\section{REFERÊNCIAS}

AdeS. Disponível em <https://www.facebook.com/notes/ades-brasil/comunicado-de200313/580350071983022>. Acesso em: 05 jun. 2013.

AdeS. Disponível em <https://www.facebook.com/notes/ades-brasil/comunicado-importantepara-os-nossos-consumidores/577404928944203>. Acesso em: 05 jun. 2013.

AdeS. Disponível em: <https://www.facebook.com/adesbrasil?ref=ts\&fref=ts>. Acesso em: 05 jun. 2013. 
BUENO, Wilson da Costa. A comunicação empresarial estratégica: definindo os contornos de um conceito. Conexão - Comunicação e Cultura, UCS, Caxias do Sul, v. 4, n. 7, p. 11-20, jan./jun. 2005. Disponível em:

<http://www.ucs.br/etc/revistas/index.php/conexao/article/viewFile/146/137>. Acesso em: 22 set. 2014.

FORNI, João José. Na crise, melhor prevenir do que remediar. Disponível em:

<http://jforni.jor.br/forni/files/Na\%20crise,\%20melhor\%20prevenir\%20do\%20que\%20remediar.p df>. Acesso em: 22 set. 2014.

LÜDKE, Menga; ANDRÉ, Marli E. D. A. Pesquisa em educação: abordagens qualitativas. São Paulo: EPU, 1986.

MARCONI, Marina de Andrade; LAKATOS, Eva Maria. Fundamentos de metodologia científica. 7.ed. São Paulo: Atlas, 2010.

MARCONI, Marina de Andrade; LAKATOS, Eva Maria. Metodologia científica. 4.ed. São Paulo: Atlas, 2006.

NEVES, Maria Luisa Timoni Camargo. Comunicação de Crise: A atuação da assessoria de imprensa da VARIG e a sua imagem na cobertura da Folha de S. Paulo. Disponível em:

<http://jforni.jor.br/forni/files/Manual\%20para\%20gerenciamento\%20de\%20crise\%20em\%20com unica\%C3\%A7\%C3\%A3o.pdf>. Acesso em: 05 jun. 2013

SOUSA, Dijanira Goulart. Manual para gerenciamento de crise em comunicação. Disponível em: <http://jforni.jor.br/forni/files/Manual\%20para\%20gerenciamento\%20de\%20crise\%20em\%20com unica\%C3\%A7\%C3\%A3o.pdf>. Acesso em: 05 jun. 2013. 